\title{
Predictors of acute kidney insufficiency post isolated coronary artery bypass grafting surgery
}

\author{
Waleed Aty ${ }^{1,2^{*}}$, Eric Lo ${ }^{1}$, Wei Xuan ${ }^{3}$, Rebecca J. Dignan ${ }^{1,3}$, Bruce French ${ }^{1}$ and Rebecca Verchin ${ }^{1}$
}

\begin{abstract}
Background: Despite the advances of cardiac surgery in the last decades, the incidence of acute kidney insufficiency (AKI) post isolated coronary artery bypass grafting surgery (iCABG) is increasing. The purpose of this study was to identify the potential predictors of postoperative AKI in ICABG in order to implement measures to reduce its incidence.

Results: We reviewed the data of 1914 patients who had on-pump iCABG from January 2008 to December 2015, using the cardiothoracic surgery unit database of Liverpool Hospital, Sydney, New South Wales, Australia. Patients were divided into two groups according to the occurrence of postoperative AKI. The incidence of postoperative AKI was $5.3 \%$ in 8 years $(n=101 / 1914$ patients). Multivariable analysis has identified the following independent predictors of postoperative AKl; age older than 80 years (OR 4.27; 95\% Cl 1.6-11.81) $(p<0.005)$, diabetes mellitus (OR 1.96; 95\% Cl 1.073-3.65) ( $p=0.034)$, peripheral vascular disease (OR 2.55; 95\% Cl 1.16-5.59) $(p<0.01)$, severe congestive cardiac symptoms (i.e., NYHA III \& IV) (OR 1.9; 95\% Cl 1.26-2.92) ( $p=0.002)$, surgical re-exploration (OR 2.49; $95 \% \mathrm{Cl}$ $1.07-5.76)(p=0.04)$, postoperative red blood cell (RBC) transfusion (OR 4.93; 95\% Cl 2.25-10.80) $(p<0.0001)$, and postoperative low cardiac output syndrome (OR 2.85; 95\% Cl 1.49-5.46) $(p<0.0001)$.
\end{abstract}

Conclusion: Postoperative AKI after iCABG is a complex problem. Predictors of postoperative AKI can be mitigated by accurate risk-based assessment and intraoperative proper surgical hemostasis.

Keywords: Acute kidney insufficiency, Isolated coronary artery bypass grafting surgery, Postoperative blood transfusion

\section{Background}

Acute kidney insufficiency (AKI) post isolated coronary artery bypass grafting surgery (iCABG) is a serious complication associated with increased morbidity and mortality [1-6]. Despite the advancements achieved in cardiac surgery and postoperative care, the incidence of AKI is increasing [6]. The reported incidence of AKI after cardiac surgery ranged between 2.4 and $40 \%$; this variability is attributed to different AKI definitions and patients' characteristics among studies [7-10]. AKI increased hospital mortality by $10-30 \%$, and it can be as high as $40-60 \%$ if continuous renal replacement therapy (CRRT) was required $[11,12]$.

\footnotetext{
* Correspondence: waleedaty@yahoo.com.au

'Department of Cardiac Surgery, Liverpool Hospital, Level 1, New Clinical Building, Elizabeth St, Liverpool, Sydney, New South Wales, Australia ${ }^{2}$ Department of Cardiac Surgery, Faculty of Medicine, Suez Canal University, Ismailia, Egypt

Full list of author information is available at the end of the article
}

The aim of this study was to identify the potential risk factors of postoperative AKI in patients undergoing iCABG in order to implement measures to reduce its incidence in high-risk patients.

\section{Methods}

Study design and data collection

This is a retrospective cohort study performed at the Cardiothoracic Surgery Unit - Liverpool Hospital, Sydney, New South Wales, Australia. Data were retrieved from the prospectively maintained database collected at the time of surgery using the questionnaire of the Australian and New Zealand Society of Cardiac and Thoracic Surgeons (ANZSCTS) database. An "opt- out" consent and information sheet were utilized. This study was approved by the Sydney South West Area Health Service Human Research Ethics Committee (Western Zone, HREC reference number: HE17/015) 
The definition of new AKI and grouping

The last serum creatinine prior to cardiac surgery and the highest postoperative serum creatinine prior to discharge were used to define the stage of AKI. AKI stages were defined by Acute Kidney Injury Network (AKIN) definitions as follows: stage 1: $50 \%$ increase in serum creatinine from baseline, stage 2: a 2 -fold increase in serum creatinine, and stage 3: a 3-fold increase in serum creatinine or a new dialysis-dependent renal failure.

Because of the small proportion of patients with new AKI, we merged stages 1,2 , and 3 in one group (AKI group), and patients with normal postoperative serum creatinine were designated as No AKI group.

\section{Patients}

All iCABG patients operated between January 2008 to December 2015 were included in the study $(n=1914)$. Patients with new AKI $(n=101)$ were compared to patients with No AKI $(n=1813)$. Patients who had offpump CABG or concomitant valve surgery with CABG were excluded to create homogenous cohort of patients. Factors investigated included age; gender; comorbidities; perioperative baseline data including the clinical status; operative data including cardiopulmonary bypass, aortic cross clamp times; and need for intra-aortic balloon pump (IABP); and postoperative data which could be associated with the development of postoperative AKI.

\section{Statistical analysis}

Continuous variables were presented as mean \pm standard deviation (SD) and categorical data as frequencies and percent. A chi-square test was used to investigate the association between the presence of AKI and the categorical risk factors. Student's $t$ test and the Wilcoxon rank-sum test were used to compare continuous variables between AKI and No AKI groups. For the dichotomized outcome variable (AKI presence/absence), multivariable logistic regression analysis was implemented to investigate the independent predictors of postoperative AKI. All analyses were performed using SAS statistical software (SAS v9.4; SAS Institute, Cary, North Carolina, USA), and $p$ value < 0.05 was considered statistically significant.

\section{Results}

\section{Patients' characteristics and operative data}

Incidence of AKI post iCABG was 5.3\% ( $n=101 / 1914$ patients) during the study period. Comparison of the patients' demographic and perioperative characteristics between patients with and without postoperative AKI is shown in Table 1.

Patients who had postoperative AKI were significantly older $(p<0.0001)$, smoker $(p=0.04)$, hypertensives $(p=$ $0.0008)$, and diabetics $(p<0.0001)$ and had more peripheral vascular disease $(p=0.0003)$, had recent MI $(p<0.0001)$,
Table 1 Comparisons of demographic and clinical variables in patients with and without postoperative $A K I$ in isolated CABG cohort

\begin{tabular}{|c|c|c|c|}
\hline Variables & $\begin{array}{l}\text { No AKI group } \\
\text { (N 1813) }\end{array}$ & $\begin{array}{l}\text { AKI group } \\
(N \text { 101) }\end{array}$ & $p$ value \\
\hline \multicolumn{4}{|l|}{ Age, years } \\
\hline$\leq 65$ & $925(51.02)$ & $30(29.7)$ & \\
\hline $65-80$ & $788(43.5)$ & $56(55.5)$ & \\
\hline$>80$ & $100(5.5)$ & $15(14.9)$ & $<0.0001$ \\
\hline Gender (male) & $1490(77.9)$ & $80(79.2)$ & 0.44 \\
\hline Body mass index $\left(\mathrm{kg} / \mathrm{m}^{2}\right)$ & $30.2 \pm 17.3$ & $30.1 \pm 14.9$ & 0.99 \\
\hline Positive smoking history & $1231(67.9)$ & $59(58.4)$ & 0.04 \\
\hline Family history of IHD & $803(44.4)$ & 45 (44.6) & 0.96 \\
\hline Hypertension & $1488(82.1)$ & $96(95.1)$ & 0.0008 \\
\hline Dyslipidemia & $1529(84.4)$ & $88(87.1)$ & 0.45 \\
\hline Respiratory disease & $323(16.9)$ & $21(20.8)$ & 0.67 \\
\hline Diabetes mellitus & $770(42.5)$ & $65(64.4)$ & $<0.0001$ \\
\hline Cerebrovascular disease & $152(8.4)$ & $14(13.9)$ & 0.057 \\
\hline Peripheral vascular disease & $149(8.2)$ & 19 (18.8) & 0.0003 \\
\hline $\begin{array}{l}\text { Acute myocardial infarction } \\
<30 \text { days }\end{array}$ & $1133(62.5)$ & $75(74.3)$ & 0.017 \\
\hline Moderate to severe LVD & $304(16.8)$ & $24(24.1)$ & 0.06 \\
\hline Congestive heart failure & $232(12.8)$ & $31(30.7)$ & $<0.0001$ \\
\hline Cardiogenic shock & $39(2.2)$ & $10(9.9)$ & $<0.0001$ \\
\hline NYHA grade III \& IV & $137(7.6)$ & $23(22.8)$ & $<0.0001$ \\
\hline \multicolumn{4}{|l|}{ Urgency of surgery } \\
\hline Elective & $1225(67.6)$ & $65(64.4)$ & \\
\hline Urgent & $507(28.0)$ & $25(24.8)$ & \\
\hline Emergent & $80(4.4)$ & $8(7.9)$ & $<0.0001$ \\
\hline CPB time (min) & $100.76 \pm 47.39$ & $106 \pm 56.8$ & 0.23 \\
\hline Aortic cross clamp time (min) & $71.3 \pm 31.2$ & $69.3(39.3)$ & 0.54 \\
\hline Intra-aortic balloon pump & $100(5.5)$ & $20(19.8)$ & $<0.0001$ \\
\hline
\end{tabular}

Categorical variables are presented as number (\%) and continuous variables as mean (SD)

$A K I$ acute kidney insufficiency, $C A B G$ coronary artery bypass grafting, $I H D$ ischemic heart disease, LVD left ventricular dysfunction, NYHA New York Heart Association, $C P B$ cardiopulmonary bypass

had congestive heart failure symptoms (NYHA III \& IV) $(p<0.0001)$, had severe left ventricular dysfunction $(p<$ $0.0001)$, and had cardiogenic shock $(p<0.0001)$.

\section{Postoperative data}

Postoperatively, the patients in the AKI group had more cardiac support with IABP $(p<0.0001)$, inotropic support, blood transfusion $(p<0.0001)$, and more frequent surgical re-exploration $(p<0.0001)$ (Table 2$)$.

\section{Predictors of AKI}

A multivariable logistic regression analysis model was constructed using variables presented in Table 3, and it 
Table 2 Comparison of postoperative variables between the AKI group and No AKI group

\begin{tabular}{llll}
\hline Variable & No AKI group & AKI group & $p$ value \\
\hline Return for exploration & $70(3.9)$ & $22(21.8)$ & $<0.0001$ \\
Low cardiac out put & $370(20.4)$ & $53(52.5)$ & $<0.0001$ \\
Vasoplegic shock & $387(21.4)$ & $40(39.6)$ & $<0.0001$ \\
Blood product transfusion & & & \\
$\quad$ Red blood cell & $605(33.4)$ & $76(75.3)$ & $<0.0001$ \\
$\quad$ Other blood product & $449(24.8)$ & $52(51.5)$ & $<0.0001$
\end{tabular}

Categorical variables are presented as $n(\%)$ and continuous variables as mean \pm SD $A K I$ acute kidney insufficiency

identified the following risk factors as predictors of postoperative AKI after iCABG (Table 3): age above 80 years (OR 4.27; 95\% CI 1.6-11.81), diabetes mellitus (OR 1.96; 95\% CI 1.073-3.65), peripheral vascular disease (OR 2.55; 95\% CI 1.16-5.59), severe congestive cardiac symptoms (NYHA III \& IV) (OR 1.9; 95\% CI 1.26-2.92), surgical re-exploration (OR 2.49; 95\% CI 1.07-5.76),

Table 3 Multivariable analysis of predictors of postoperative acute kidney insufficiency (AKI) in isolated coronary artery bypass grafting

\begin{tabular}{|c|c|c|}
\hline Variables & $\begin{array}{l}\text { Adjusted } \\
\text { OR }(95 \% \mathrm{Cl})\end{array}$ & $p$ value \\
\hline \multicolumn{3}{|l|}{ Age, years } \\
\hline$\leq 65$ & Reference value & \\
\hline $65-80$ & $1.4(0.7-3.1)$ & 0.39 \\
\hline$>80$ & $4.27(1.6-11.8)$ & 0.005 \\
\hline Smoking & $0.64(0.3-1.2)$ & 0.17 \\
\hline Diabetes mellitus & $1.96(1.1-3.7)$ & 0.04 \\
\hline Cerebrovascular disease & $0.94(0.4-2.4)$ & 0.94 \\
\hline Peripheral vascular disease & $2.55(1.2-5.6)$ & 0.02 \\
\hline Acute myocardial infarction $<30$ days & $1.48(0.7-2.9)$ & 0.27 \\
\hline History of congestive heart failure & $0.80(0.4-1.9)$ & 0.64 \\
\hline NYHA III \& IV & $1.90(1.3-2.9)$ & 0.002 \\
\hline Cardiogenic shock & $0.34(0.3-2.9)$ & 0.16 \\
\hline \multicolumn{3}{|l|}{ Urgency } \\
\hline Elective & Reference value & \\
\hline Urgent & $0.56(0.3-1.2)$ & 0.12 \\
\hline Emergency & $0.70(0.2-2.4)$ & 0.56 \\
\hline Use intra-aortic balloon pump & $0.98(0.3-2.9)$ & 0.97 \\
\hline Surgical re-exploration & $2.49(1.1-5.8)$ & 0.04 \\
\hline Postoperative atrial fibrillation & $1.54(0.8-2.9)$ & 0.19 \\
\hline Postoperative low cardiac output syndrome & $2.85(1.5-5.5)$ & $<0.0001$ \\
\hline \multicolumn{3}{|l|}{ Blood product transfusion } \\
\hline Red blood cells & $4.93(2.3-10.8)$ & $<0.0001$ \\
\hline Other blood products & $0.65(0.1-1.3)$ & 0.24 \\
\hline
\end{tabular}

Cl confidence interval, OR odds ratio, NYHA New York Heart Association postoperative red blood cell (RBC) transfusion (OR 4.93; 95\% CI 2.25-10.80), and postoperative low cardiac output syndrome (OR 2.85; 95\% CI 1.49-5.46).

\section{Discussion}

In this study, the incidence of AKI was 5.2\% which is higher than the expected for the isolated CABG but lies within the reported range (2.4-40\%) of AKI after cardiac surgery $[1,5,6,8,10,13-16]$. The higher incidence of AKI in our study could be explained by merging patients with different AKIN stages into one stage. The variation in the incidence of AKI in literature is likely due to two reasons: a lack of universal definition for postoperative AKI and difference in patient population among studies. Warren and colleagues defined AKI as the rise in creatinine $25 \%$ from baseline or an absolute increase of $>$ $0.5 \mathrm{mg} / \mathrm{dL}$ [6]. Other studies used different equations to calculate the effective glomerular filtration rate (EGFR) and then defined the AKI according to the change in the pre- and postoperative EGFR [10]. AKI definition in other studies was based on the calculated creatinine clearance [8]. In a large cohort, Chertow and associates defined AKI as the deterioration of the renal function sufficient to require dialysis within 30 days after surgery [13]. The difference in the demographics and operative variations of the studied populations affected the occurrence of postoperative AKI; previous studies included the results of valvular and combined cardiac surgeries which are more complex than iCABG $[5,7-13,17]$. Despite the advances in cardiac surgery and postoperative care in the last decades, the incidence of postoperative AKI is increasing which may be explained by the increased number of high-risk patients undergoing iCABG in recent decades making them vulnerable to postoperative AKI $[1,6]$.

The pathogenesis of AKI after iCABG is still not fully understood and likely multifactorial. In general, it requires combinations of risk factors as well as several intraoperative or postoperative insults. The independent risk factors for AKI identified in this cohort were age above 80 years, diabetes mellitus, peripheral vascular disease, and the presence of congestive heart failure symptoms. Similar findings were reported in our previous study and other studies [18-20]. Unsurprisingly, the combination of elderly, diabetics, and patients with vascular disease predisposed patient to AKI with minimal insult. These are non-modifiable multi-systemic risk factors which affected both heart, kidney and neurovascular systems. In our institute, we did not use any preoperative risk stratification algorithms $[9,21,22]$ to predict and identify high-risk patients who were vulnerable to have AKI and could benefit from peri- or intraoperative renal protective strategies. Huen and their colleagues 
concluded in their reviews that these scoring systems require more validation across huge cohorts in different centers before being adopted [9].

Operative factor predicting AKI in this cohort was emergency surgery. Patients who suffer from inadequate renal perfusion due to acute coronary syndrome and cardiogenic shock are often associated with postoperative low cardiac output syndrome which causes renal hypoperfusion especially to vulnerable kidneys. Additionally, operating urgently on a patient just loaded by coronary angiogram contrast dye adds more insult to those vulnerable kidneys. In recent series $[4,23$, 24], prolonged cardiopulmonary bypass was associated with postoperative AKI, a finding which was not confirmed in our study as the univariable analysis revealed no difference in $\mathrm{CPB}$ and ischemic time between AKI and No AKI groups.

We found that surgical re-exploration due to postoperative bleeding or cardiac tamponade were the most significant postoperative predictors of AKI post iCABG; this result was also reported by others [10, 25]. We assumed that postoperative surgical re-exploration exacerbated other risk factors that add more insult to the renal perfusion as hemodynamic instability, anemia, blood transfusion, and the use of vasopressors. Postoperative bleeding may also initiate multiple episodes of renal hypoperfusion due to either hypotension or cardiac tamponade. Loor and Ranucci and their colleagues found anemia to be independent predictor of postoperative AKI $[26,27]$. Anemia decreases renal oxygen delivery, impairs hemostasis and enhances oxidative stress contributing to the risk of renal insult. Anemia and blood transfusion had a synergistic effect on postoperative AKI, as there is an increasing risk of postoperative AKI in transfused anemic patient compared to non-transfuse anemic patient which was attributed to the increased risk of post-transfusion oxidative injury in anemic patients with abnormal iron metabolism [28, 29].

This study found that the transfusion of RBCs postoperatively was an independent predictor of AKI. We believed that blood transfusion was a consequence of postoperative bleeding and many studies reported that stored RBC transfusions contributed to organ dysfunction in borderline patients. Stored RBCs have no ability to generate nitric osxide, increasing its adhesive power to the vascular endothelium which may result in impairment of tissue oxygen delivery, increasing oxygen oxidative stress and coagulation cascade which may contribute to the establishment of postoperative AKI [28-30].

\section{Study limitations}

This study was a retrospective and observational study, and therefore, the conclusion drawn should be considered according to these constraints. Because of the inclusion of on-pump isolated CABG only, our results cannot be generalized to other populations; additionally, the small number of events compared to the variables included in the logistic regression model added more limitation to this study. The effect of unknown confounders on the observed associations between the risk factors and AKI, such as contrast used in coronary angiogram and CT scan, perioperative and postoperative use of nephrotoxic medication, hydration state or perioperative anemia, intraoperative hypotension, the effect of $\mathrm{CPB}$, and intraoperative hematocrit level, cannot be ruled out. It is difficult to implicate or conclude a temporal relationship between AKI and $\mathrm{iCABG}$ and whether all AKI events in iCABG were due to correlation and not a causation

\section{Conclusion}

This study identified the predictors of acute kidney insufficiency after isolated CABG. Older patients with non-modifiable comorbidities such as diabetes mellitus, peripheral vascular disease, and symptomatic heart failure could be identified preoperatively and should have accurate risk-based assessments to give the patients and their families accurate risk prediction; moreover, measures can be put in place by the heart team to decrease the risk of postoperative AKI. Postoperative predictors can be mitigated by preoperative optimization of hemoglobin levels, coagulation profiles, and proper surgical hemostasis.

\section{Abbreviations}

AKI: Acute kidney insufficiency; CABG: Coronary artery bypass grafting; iCABG: Isolated coronary artery bypass grafting; IHD: Ischemic heart disease; LVD: Left ventricular dysfunction; NYHA: New York Heart Association; IABP: Intra-aortic balloon pump; AKIN: Acute Kidney Injury Network; CPB: Cardiopulmonary bypass; $\mathrm{M} \pm \mathrm{SD}$ : Mean and standard deviation; Cl: Confidence interval; OR: Odds ratio; ANZSCTS: Australian and New Zealand Society of Cardiac and Thoracic Surgeons; CRRT: Continuous renal replacement therapy

\section{Acknowledgements}

Not applicable

\section{Authors' contributions}

WA wrote the study protocol. RD and BF reviewed the protocol before it was submitted to the ethics committee. WA and RV reviewed and collected the missing data. WA and XW did the statistical analysis. WA and ER wrote the manuscript. All authors read and approved the manuscript for submission and publications.

\section{Funding}

This study did not receive any funding.

\section{Availability of data and materials}

The datasets used and/or analyzed during the current study are available from the corresponding author on reasonable request.

Ethics approval and consent to participate

This study was approved by the Sydney South West Area Health Service Human Research Ethics Committee (Western Zone, HREC reference number: 
HE17/015). All patients signed informed written consent to participate in this study and to publish the results of this study.

\section{Consent for publication}

All patients signed an informed written consent for publication.

\section{Competing interests}

The authors declare that they have no competing interests.

\section{Author details}

'Department of Cardiac Surgery, Liverpool Hospital, Level 1, New Clinical Building, Elizabeth St, Liverpool, Sydney, New South Wales, Australia. ${ }^{2}$ Department of Cardiac Surgery, Faculty of Medicine, Suez Canal University, Ismailia, Egypt. ${ }^{3}$ Sydney Southwest Clinical School, University of New South Wales, Liverpool, New South Wales, Australia.

Received: 25 May 2019 Accepted: 29 July 2019

Published online: 19 August 2019

\section{References}

1. ElBardissi AW, Aranki SF, Sheng S, O'Brien SM, Greenberg CC, Gammie JS (2012) Trends in isolated coronary artery bypass grafting: an analysis of the Society of Thoracic Surgeons adult cardiac surgery database. J Thorac Cardiovasc Surg 143(2):273-281

2. Gelsomino S, Del Pace S, Parise O, Caciolli S, Matteucci F, Fradella G et al (2017) Impact of renal function impairment assessed by CKDEPI estimated glomerular filtration rate on early and late outcomes after coronary artery bypass grafting. Int J Cardiol 227:778-787

3. Liotta M, Olsson D, Sartipy U, Holzmann MJ (2014) Minimal changes in postoperative creatinine values and early and late mortality and cardiovascular events after coronary artery bypass grafting. Am J Cardiol 113(1):70-75

4. Pickering JW, James MT, Palmer SC (2015) Acute kidney injury and prognosis after cardiopulmonary bypass: a meta-analysis of cohort studies. Am J Kidney Dis 65(2):283-293

5. Thakar CV, Worley S, Arrigain S, Yared JP, Paganini EP (2005) Influence of renal dysfunction on mortality after cardiac surgery: modifying effect of preoperative renal function. Kidney Int 67(3):1112-1119

6. Warren J, Mehran R, Baber U, Xu K, Giacoppo D, Gersh BJ et al (2016) Incidence and impact of acute kidney injury in patients with acute coronary syndromes treated with coronary artery bypass grafting: insights from the Harmonizing Outcomes With Revascularization and Stents in Acute Myocardial Infarction (HORIZONS-AMI) and Acute Catheterization and Urgent Intervention Triage Strategy (ACUITY) trials. Am Heart J 171(1):40-47

7. Coca SG, Yusuf B, Shlipak MG, Garg AX, Parikh CR (2009) Long-term risk of mortality and other adverse outcomes after acute kidney injury: a systematic review and meta-analysis. Am J Kidney Dis 53(6):961-973

8. Doddakula K, Al-Sarraf N, Gately K, Hughes A, Tolan M, Young V et al (2007) Predictors of acute renal failure requiring renal replacement therapy post cardiac surgery in patients with preoperatively normal renal function. Interact Cardiovasc Thorac Surg 6(3):314-318

9. Huen SC, Parikh CR (2012) Predicting acute kidney injury after cardiac surgery: a systematic review. Ann Thorac Surg 93(1):337-347

10. Karkouti K, Wijeysundera DN, Yau TM, Callum JL, Cheng DC, Crowther M et al (2009) Acute kidney injury after cardiac surgery: focus on modifiable risk factors. Circulation 119(4):495-502

11. Mangano CM, Diamondstone LS, Ramsay JG, Aggarwal A, Herskowitz A, Mangano DT (1998) Renal dysfunction after myocardial revascularization: risk factors, adverse outcomes, and hospital resource utilization. The Multicenter Study of Perioperative Ischemia Research Group. Ann Intern Med 128(3):194-203

12. Ryden L, Sartipy U, Evans M, Holzmann MJ (2014) Acute kidney injury after coronary artery bypass grafting and long-term risk of end-stage renal disease. Circulation 130(23):2005-2011

13. Chertow GM, Levy EM, Hammermeister KE, Grover F, Daley J (1998) Independent association between acute renal failure and mortality following cardiac surgery. Am J Med 104(4):343-348

14. Cooper WA, O'Brien SM, Thourani VH, Guyton RA, Bridges CR, Szczech LA et al (2006) Impact of renal dysfunction on outcomes of coronary artery bypass surgery: results from the Society of Thoracic Surgeons National Adult Cardiac Database. Circulation 113(8):1063-1070
15. Lagny MG, Jouret F, Koch JN, Blaffart F, Donneau AF, Albert A et al (2015) Incidence and outcomes of acute kidney injury after cardiac surgery using either criteria of the RIFLE classification. BMC Nephrology 16:76

16. Rosner MH, Okusa MD (2006) Acute kidney injury associated with cardiac surgery. Clin J Am Soc Nephrol 1(1):19-32

17. O'Neal JB, Shaw AD, FTt B (2016) Acute kidney injury following cardiac surgery: current understanding and future directions. Crit Care (London, England). 20(1):187

18. Ahmed WA, Tully PJ, Baker RA, Knight UL (2009) Survival after isolated coronary artery bypass grafting in patients with severe left ventricular dysfunction. Ann Thorac Surg 87(4):1106-1112

19. Chertow GM, Lazarus JM, Christiansen CL, Cook EF, Hammermeister KE, Grover F et al (1997) Preoperative renal risk stratification. Circulation 95(4): 878-884

20. Fortescue EB, Bates DW, Chertow GM (2000) Predicting acute renal failure after coronary bypass surgery: cross-validation of two risk-stratification algorithms. Kidney Int 57(6):2594-2602

21. Eriksen BO, Hoff KR, Solberg S (2003) Prediction of acute renal failure after cardiac surgery: retrospective cross-validation of a clinical algorithm. Nephrol Dial Transplant 18(1):77-81

22. Thakar CV, Arrigain S, Worley S, Yared JP, Paganini EP (2005) A clinical score to predict acute renal failure after cardiac surgery. J Am Soc Nephrol 16(1): $162-168$

23. Axtell AL, Fiedler AG, Melnitchouk S, D'Alessandro DA, Villavicencio MA Jassar AS et al Correlation of Cardiopulmonary Bypass Duration with Acute Renal Failure after Cardiac Surgery. J Thorac Cardiovasc Surg

24. Li Z, Fan G, Zheng X, Gong X, Chen T, Liu X et al (2019) Risk factors and clinical significance of acute kidney injury after on-pump or off-pump coronary artery bypass grafting: a propensity score-matched study. Interact Cardiovasc Thorac Surg

25. Moulton MJ, Creswell LL, Mackey ME, Cox JL, Rosenbloom M (1996) Reexploration for bleeding is a risk factor for adverse outcomes after cardiac operations. J Thorac Cardiovasc Surg 111(5):1037-1046

26. Loor G, Li L, Sabik JF 3rd, Rajeswaran J, Blackstone EH, Koch CG (2012) Nadir hematocrit during cardiopulmonary bypass: end-organ dysfunction and mortality. J Thorac Cardiovasc Surg 144(3):654-662 e4

27. Ranucci M, Conti D, Castelvecchio S, Menicanti L, Frigiola A, Ballotta A et al (2010) Hematocrit on cardiopulmonary bypass and outcome after coronary surgery in nontransfused patients. Ann Thorac Surg 89(1):11-17

28. Karkouti $K$ (2012) Transfusion and risk of acute kidney injury in cardiac surgery. Br J Anaesth 109 Suppl 1:i29-i38

29. Karkouti K, Wijeysundera DN, Yau TM, McCluskey SA, Chan CT, Wong PY et al (2011) Influence of erythrocyte transfusion on the risk of acute kidney injury after cardiac surgery differs in anemic and nonanemic patients. Anesthesiology 115(3):523-530

30. Cardo L, Hmel P, Wilder D (2008) Stored packed red blood cells contain a procoagulant phospholipid reducible by leukodepletion filters and washing. Transfus Apher Sci 38(2):141-147

\section{Publisher's Note}

Springer Nature remains neutral with regard to jurisdictional claims in published maps and institutional affiliations.

\section{Submit your manuscript to a SpringerOpen ${ }^{\circ}$ journal and benefit from:}

- Convenient online submission

- Rigorous peer review

- Open access: articles freely available online

- High visibility within the field

- Retaining the copyright to your article

Submit your next manuscript at $>$ springeropen.com 